\title{
MODEL CONSTRUCTION
}

To explore the likely behavior of the carbonate and conodont calcium isotope records, we used a simplified box model of the global calcium cycle, presented previously by Payne et al. (2010) and comparable to models presented in several other studies (e.g., Blättler et al. 2011; Farkas et al. 2007). In the model, the ocean is treated as a single box with the fluxes of calcium to the ocean being river input, hydrothermal alteration of the ocean crust, and diffusion/dewatering from pore fluid and the main sink being the deposition of carbonate minerals. The equation for the change in calcium concentration with time is:

$$
\frac{d M_{C a}}{d t}=\text { Flux }_{\text {in }}-\text { Flux }_{\text {out }}=F_{\text {riv }}+F_{\text {hyd }}+F_{p w}-F_{\text {carb }}
$$

The river, hydrothermal, and pore water fluxes are prescribed $\left(F_{r i v}, F_{h y d}, F_{p w}\right)$ and the carbonate sink is prescribed as proportional to the square of the ratio between the current concentration of calcium in the ocean and the steady-state (equilibrium) value. This approach assumes a constant carbonate ion concentration in seawater, which is unlikely under some model scenarios (e.g., acidification). However, the model is intended to illustrate the qualitative differences in calcium isotope variation of carbonate minerals and conodont microfossils, rather than to quantitatively reproduce the observed record. Consequently, we view the model as a useful tool for interpreting the calcium isotope record rather than an attempt to reproduce historical biogeochemical cycling to high accuracy. Each of the fluxes was assigned a calcium isotope composition $\left(\delta^{44 / 40} \mathrm{Ca}\right)$ such that the changes in calcium concentration and $8^{44 / 40} \mathrm{Ca}$ could be modeled simultaneously. The equation used is:

$$
\frac{d\left(M_{C a} \delta_{s w}\right)}{d t}=F_{r i v} \cdot\left(\delta_{r i v}-\delta_{s w}\right)+F_{h y d} \cdot\left(\delta_{h y d}-\delta_{s w}\right)+F_{p w} \cdot\left(\delta_{p w}-\delta_{s w}\right)-F_{c a r b} \cdot \varepsilon_{c a r b}
$$

where $\delta_{S W}$ is the $\delta^{44 / 40} \mathrm{Ca}$ of seawater, $\delta_{\text {riv }} \delta_{h y d} \delta_{p w}$ are the $\delta^{44 / 40} \mathrm{Ca}$ of rivers, hydrothermal input, and porewaters respectively, and $\varepsilon_{c a r b}$ is the fractionation factor between seawater and carbonate minerals. The values used for each of these fluxes in the latest Permian are listed in Table 3. This equation was presented incorrectly in the supporting online materials for Payne et al. (2010: SOM Eqn. 4) and is corrected here.

We solved equation (2) above using finite differences with a time step of 1000 years and ran the model for 5 million years to generate predictions under the various scenarios presented in Figure 1. The model runs have been described previously in Payne et al. (2010). No model run is required for the local shift in mineralogy, as the shape of the local carbonate calcium isotope curve has no effect on the isotope composition of seawater. In Figure 1, we illustrate a negative excursion in the calcium isotope composition of carbonates for agreement with the known PermianTriassic calcium isotope record. 
In Figures 1 and $2, \delta^{44 / 40} \mathrm{Ca}$ are normalized to the bulk silicate earth (BSE) reference material, meaning $\delta^{44 / 40}$ Casmow is approximately $0.7 \%$.

\section{MATERIALS AND METHODS}

Sample preparation. We analyzed 23 sets of well-preserved conodont elements from the Meishan section in southeastern China, the Global Stratotype Section and Point (GSSP) for the Permian-Triassic boundary. Conodonts were extracted from bulk rock using crushing, acetic acid treatment, and heavy liquid separation to isolate elements. Individual elements were handpicked to remove other particles that passed through the heavy liquid. Before cleaning, a threshold weight of over $100 \mu \mathrm{g}$ of conodont material was imposed to ensure that at least $30 \mu \mathrm{g}$ Ca would be present in each sample. Assuming the conodonts are approximately $40 \% \mathrm{Ca}$, a $10 \mu \mathrm{g}$ safeguard was included in case material was lost during the cleaning or other phases of sample preparation.

First, elements were rinsed in $1 \mathrm{~mL}$ distilled acetone to remove any glue or adhered clay particles, followed by three rinses in $1 \mathrm{~mL} 0.2 \mathrm{M} \mathrm{NH}_{4} \mathrm{Ac}$ to replace exchangeable $\mathrm{Ca}$ and $\mathrm{Sr}$ on clays and conodont surfaces with $\mathrm{NH}_{4}$. A final rinse in $1 \mathrm{~mL}$ 1.4 M HAc dissolved any carbonate phases. Between all chemical rinses, conodont elements were ultrasonically bathed twice in $1 \mathrm{~mL}$ nanopure water $(>18 \mathrm{Mohm} / \mathrm{cm})$ and waste fluid was extracted by pipette. Once cleaned, conodont elements were dissolved in $3.5 \mathrm{M} \mathrm{HNO}_{3}$ and dried down.

Calcium isotopes. The dissolved elements were then spiked with a double spike of ${ }^{42} \mathrm{Ca}-{ }^{48} \mathrm{Ca}\left({ }^{42} \mathrm{Ca} /{ }^{48} \mathrm{Ca} \approx 0.7\right)$ in order to correct for mass discrimination during the thermal ionization mass spectrometry (TIMS) analysis. The spiked solution was then dried down and re-dissolved in $\mathrm{HNO}_{3}$. Calcium was purified using $200 \mu \mathrm{l}$ of DGA resin with 3 M HNO3 and water as the eluents (Nielsen et al., 2011). Procedural blanks are on the order of 1 nanogram, $<<0.1 \%$ of our smallest sample size.

Samples were dried down and redissolved in $3 \mathrm{~N} \mathrm{HNO}_{3}$, then loaded in quantities of $\sim 3 \mu \mathrm{g}$ Ca onto degassed, zone-refined Re in a double filament configuration. The samples were dried by introducing a current to the filament at approximately $0.75-$ 1.0 ampere (A) for about a minute. Samples were then capped with $0.5 \mu \mathrm{l}$ of $40 \%$ $\mathrm{H}_{3} \mathrm{PO}_{4}$ and heated to "dull red."

Ca-loaded filaments were run in a ThermoFinnigan Triton multi-collector TIMS at the Center for Isotope Geochemistry at the University of California, Berkeley. Ca isotope values are expressed as permil (\%) relative to the bulk Earth standard reference material with a ${ }^{44} \mathrm{Ca} /{ }^{40} \mathrm{Ca}$ value of 0.0212094 (Simon and DePaolo, 2010). 
All samples were run at least twice, and uncertainty is reported as the $2 \sigma$ error of the replicates. The two standard error uncertainty across replicates was $\leq 0.1 \%$ for most of the samples, but reproducibility for some samples is worse and limited sample material prevented further analyses. Replicate measurements of the standard indicate a minimum uncertainty of $0.08 \%$ for all samples. Three replicates of SRM915A were analyzed in each sample turret to identify and account for long-term instrument drift.

Strontium isotopes. Strontium isotope analyses of Meishan conodonts and Dajiang carbonates were conducted according to procedures described in Fantle and DePaolo (2006). Stratigraphic information regarding the Dajiang carbonates is presented in Payne et al. (2010). Following ion exchange separation using Sr Spec resin in acid-washed Teflon columns, samples of $100 \mathrm{ng}$ dissolved $\mathrm{Sr}$ in $1 \% \mathrm{H}_{3} \mathrm{PO}_{4}$ were loaded with a $\mathrm{TaCl}$ activator onto a zone-refined Re filament. Measurements were conducted on a Finnegan Triton multicollector thermal ionization mass spectrometer in static mode. The ${ }^{88} \mathrm{Sr}^{+}$beam intensity is between 3 and $6 \mathrm{~V}$ during analysis, which collects data over $100-200$ scans. Peaks are monitored at ${ }^{88} \mathrm{Sr},{ }^{87} \mathrm{Sr}$, ${ }^{86} \mathrm{Sr},{ }^{85} \mathrm{Rb}$, and ${ }^{84} \mathrm{Sr}$. Repeated measurements of the Sr isotope standard NBS-987 on the Triton over a 4-month period (August-December 2011 ) yield ${ }^{87} \mathrm{Sr} /{ }^{86} \mathrm{Sr}=$ $0.710250+/-0.000006$ (two standard errors, $n=16$ ). Seawater measured on the Triton at Berkeley has a ${ }^{87} \mathrm{Sr} /{ }^{86} \mathrm{Sr}$ value of 0.709175.

\section{REFERENCES}

Amini, M., Eisenhauer, A., Böhm, F., Fietzke, J., Bach, W., Garbe-Schönberg, D., Rosner, M., Bock, B., Lackschewitz, K.S., and Hauff, F., 2008, Calcium isotope $\left(\delta^{44 / 40} \mathrm{Ca}\right)$ fractionation along hydrothermal pathways, Logatchev field (Mid-Atlantic Ridge, $\left.14^{\circ} 45^{\prime} \mathrm{N}\right)$ : Geochimica et Cosmochimica Acta, v. 72, p. 4107-4122, doi:10.1016/j.gca.2008.05.055.

Blättler, C.L., Jenkyns, H.C., Reynard, L.M., and Henderson, G.M., 2011, Significant increases in global weathering during Oceanic Anoxic Events $1 \mathrm{a}$ and 2 indicated by calcium isotopes: Earth and Planetary Science Letters, v. 309, p. 77-88, doi::10.1016/j.epsl.2011.06.029.

Elderfield, H., and Schultz, A., 1996, Mid-ocean ridge hydrothermal fluxes and the chemical composition of the ocean: Annual Review of Earth and Planetary Sciences, v. 24, p. 191-224, doi:10.1146/annurev.earth.24.1.191.

Fantle, M.S., and DePaolo, D.J., 2006, Sr isotopes and pore fluid chemistry in carbonate sediment of the Ontong Java Plateau: calcite recrystallization rates and evidence for a rise in seawater $\mathrm{Mg}$ over the last 10 million years: Geochimica et Cosmochimica Acta, v. 70, p. 3883-3904, doi:10.1016/j.gca.2006.06.009.

Fantle, M.S., and DePaolo, D.J., 2007, Ca isotopes in carbonate sediment and pore fluid from ODP Site 807A: the $\mathrm{Ca}^{2+}{ }_{(\mathrm{aq})}$-calcite equilibrium fractionation factor and calcite recrystallization rates in Pleistocene sediments: Geochimica et Cosmochimica Acta, v. 71, p. 2524-2546, doi:10.1016/j.gca.2007.03.006. 
Farkaš, J., Buhl, D., Blenkinsop, J., and Veizer, J., 2007, Evolution of the oceanic calcium cycle curin gthe late Mesozoic: evidence from $\delta{ }^{44 / 40} \mathrm{Ca}$ of marine skeletal carbonates: Earth and Planetary Science Letters, v. 253, p. 96-111, doi:10.1016/j.eps1.2006.10.015.

Horita, J., Zimmerman, H., and Holland, H.D., 2002, Chemical evolution of seawater during the Phanerozoic: implications from the record of marine evaporites: Geochimica et Cosmochimica Acta, v. 66, p. 3733-3756, doi:10.1016/S00167037(01)00884-5.

Nielsen, L.C., Druhan, J.L., Yang, W., Brown, S.T., and DePaolo, D.J., 2011, Calcium isotopes as tracesrs of biogeochemical processes, in Baskaran, M., ed., Handbook of Environmental Isotope Geochemistry: Berlin, Heidelberg: Springer, p. 105-124, doi:10.1007/978-3-642-10637-8_7

Opdyke, B.N., and Wilkinson, B.H., 1993 , Carbonate mineral saturation state and cratonic limestone accumulation: American Journal of Science, v. 293, p. 217-234, doi:10.2475/ajs.293.3.217.

Payne, J.L., Turchyn, A.V., Paytan, A., DePaolo, D.J., Lehrmann, D.J., Yu, M., and Wei, J., 2010, Calcium isotope constraints on the end-Permian mass extinction:

Proceedings of the National Academy of Sciences of the United States of America, v. 107, p. 8543-8548, doi:10.1073/pnas.0914065107.

Pilsen, M.E.Q., 1998, An introduction to the chemistry of the sea: Prentice Hall, Upper Saddle River, NJ.

Simon, J.I., and DePaolo, D.J., 2010, Stable calcium isotopic composition of meteorites and rocky planets: Earth and Planetary Science Letters, v. 289, p. 457-466, doi:10.1016/j.epsl.2009.11.035. 
TABLE DR1. MEISHAN $\delta^{44 / 40} \mathrm{Ca}$ ILLUSTRATED IN FIGURE 2 AND ${ }^{87} \mathrm{Sr} /{ }^{86} \mathrm{Sr}$ FOR SELECT SAMPLES

\begin{tabular}{|c|c|c|c|c|c|}
\hline $\begin{array}{l}\text { Sample } \\
\text { bed }\end{array}$ & $\begin{array}{l}\text { Stratigraphic } \\
\text { elevation }(m)\end{array}$ & $\begin{array}{l}\delta^{44 / 40} \mathrm{Ca} \\
(\% \circ \mathrm{BSE})\end{array}$ & $2 \sigma$ & ${ }^{87} \mathrm{Sr} /{ }^{86} \mathrm{Sr}$ & $2 \sigma * 10^{-6}$ \\
\hline $22-15$ & -3 & -0.60 & 0.02 & 0.707108 & 8 \\
\hline 23-1 & -1.9 & -0.62 & 0.14 & & \\
\hline $23-2$ & -1.6 & -0.68 & 0.26 & 0.707121 & 14 \\
\hline $23-5$ & -1.3 & -0.74 & 0.05 & & \\
\hline $23-9$ & -1.07 & -0.79 & 0.06 & & \\
\hline $24 a$ & -0.98 & -0.74 & 0.00 & 0.707133 & 10 \\
\hline 24b & -0.88 & -0.76 & 0.16 & & \\
\hline $24 c-1$ & -0.77 & -0.80 & 0.17 & & \\
\hline $24 d 2$ & -0.6 & -0.79 & 0.03 & 0.707201 & 9 \\
\hline $24 d 3$ & -0.5 & -0.76 & 0.18 & & \\
\hline $24 d 4$ & -0.42 & -0.65 & 0.11 & & \\
\hline $24 \mathrm{e}$ & -0.21 & -0.86 & 0.13 & & \\
\hline $24 \mathrm{f} 1$ & -0.16 & -0.72 & 0.04 & & \\
\hline $24 f 2$ & -0.14 & -0.71 & 0.01 & 0.707184 & 8 \\
\hline 25 & -0.11 & -0.79 & 0.00 & & \\
\hline 26 & -0.06 & -0.86 & 0.25 & & \\
\hline $27 b$ & 0.0 & -0.95 & 0.13 & & \\
\hline $27 c$ & 0.1 & -0.83 & 0.00 & & \\
\hline $27 d$ & 0.14 & -0.80 & 0.10 & & \\
\hline 29 & 0.2 & -0.78 & 0.19 & & \\
\hline $29-2$ & 0.23 & -0.75 & 0.16 & & \\
\hline $29-3$ & 0.3 & -0.63 & 0.09 & & \\
\hline 30 & 0.5 & -0.75 & 0.09 & & \\
\hline
\end{tabular}


TABLE DR2. DAJIANG $\delta^{44 / 40} \mathrm{Ca}$ ILLUSTRATED IN FIGURE 2 AND ${ }^{87} \mathrm{Sr} /{ }^{86} \mathrm{Sr}$ FOR SELECT SAMPLES

\begin{tabular}{|c|c|c|c|c|c|}
\hline $\begin{array}{l}\text { Sample } \\
\text { bed }\end{array}$ & $\begin{array}{l}\text { Stratigraphic } \\
\text { elevation }(m)\end{array}$ & $\begin{array}{c}\delta^{44 / 40} \mathrm{Ca} \\
(\% \text { BSE) }\end{array}$ & $2 \sigma$ & ${ }^{87} \mathrm{Sr} /{ }^{86} \mathrm{Sr}$ & $2 \sigma * 10^{-6}$ \\
\hline PDJ-001 & 0 & -0.30 & 0.22 & & \\
\hline PDJ-009 & 9 & -0.36 & 0.32 & & \\
\hline PDJ-017 & 17 & -0.19 & 0.04 & & \\
\hline PDJ-026 & 26 & -0.06 & 0.16 & 0.707163 & 5 \\
\hline PDJ-030 & 30 & -0.48 & 0.22 & 0.707521 & 17 \\
\hline PDJ-033 & 33 & -0.32 & 0.18 & & \\
\hline PDJ-040 & 39.7 & -0.42 & 0.08 & & \\
\hline PDJ-044 & 43 & -0.54 & 0.22 & 0.707438 & 84 \\
\hline PDJ-046 & 44.5 & -0.58 & 0.16 & & \\
\hline PDJ-050 & 47 & -0.64 & 0.20 & 0.707296 & 14 \\
\hline PDJ-053 & 50 & -0.69 & 0.28 & 0.707259 & 6 \\
\hline PDJ-058 & 54 & -0.51 & 0.08 & & \\
\hline PDJ-061 & 56.4 & -0.53 & 0.02 & & \\
\hline PDJ-064 & 57.4 & -0.32 & 0.04 & & \\
\hline PDJ-068 & 60 & -0.64 & 0.24 & 0.707250 & 6 \\
\hline PDJ-072 & 64 & -0.52 & 0.26 & 0.707276 & 14 \\
\hline PDJ-075 & 66 & -0.60 & 0.20 & 0.707157 & 4 \\
\hline PDJ-080 & 70.1 & -0.54 & 0.36 & & \\
\hline PDJ-081 & 71 & -0.56 & 0.10 & 0.707313 & 18 \\
\hline PDJ-090 & 80 & -0.55 & 0.10 & 0.707212 & 15 \\
\hline PDJ-100 & 87.6 & -0.65 & 0.26 & & \\
\hline PDJ-115 & 100.4 & -0.28 & 0.18 & & \\
\hline PDJ-140 & 156.2 & -0.16 & 0.04 & & \\
\hline
\end{tabular}


Table DR3. Parameter values used in calcium cycle box model. Values are the same as those used in Payne et al. (2010), through rescaled based on a revised value for the calcium isotope composition of bulk silicate Earth relative to SRM-915A (Simon and DePaolo, 2010).

\begin{tabular}{|c|c|c|}
\hline Parameter & Value and unit & Source (see Supporting References) \\
\hline$[\mathrm{Ca}]_{i}$ & $10 \mathrm{mM}$ & Horita et al. 2002 \\
\hline $\mathrm{F}_{\text {riv }}$ & $14 \times 10^{12} \mathrm{~mol} / \mathrm{yr}$ & Pilsen 1998 \\
\hline $\mathrm{F}_{\text {hyd }}$ & $4.0 \times 10^{12} \mathrm{~mol} / \mathrm{yr}$ & Elderfield and Schultz 1996 \\
\hline $\mathrm{F}_{\mathrm{pw}}$ & $6.3 \times 10^{12} \mathrm{~mol} / \mathrm{yr}$ & Pilsen 1998 \\
\hline $\mathrm{k}_{\text {carb }}$ & $24.3 \times 10^{12} \mathrm{~mol} / \mathrm{yr}$ & $\begin{array}{l}\text { To balance weathering - initial steady } \\
\text { state }\end{array}$ \\
\hline$F_{\text {carb }}$ & $\mathrm{k}_{\text {carb }} \times\left([\mathrm{Ca}]_{\mathrm{i}} /[\mathrm{Ca}]_{\mathrm{t}}\right)^{2}$ & $\begin{array}{l}\text { Feedback on calcium concentrations via } \\
\text { carbonate saturation state (Opdyke and } \\
\text { Wilkinson, 1993) }\end{array}$ \\
\hline$\delta_{\text {sw }}$ & $0.9 \%$ & Payne et al. 2010, assuming $\varepsilon_{\text {carb }}=-1.4 \%$ \\
\hline$\delta_{\text {riv }}$ & $-0.6 \%$ & $\begin{array}{l}\text { Assumes majority of calcium from } \\
\text { carbonate weathering }\end{array}$ \\
\hline$\delta_{\text {hyd }}$ & $-0.25 \%$ & Amini et al. 2008 \\
\hline$\delta_{\mathrm{pw}}$ & $-0.45 \%$ & $\begin{array}{l}\text { Approximation assuming pore fluids are } \\
\text { only slightly heavier isotopically than } \\
\text { carbonates }\end{array}$ \\
\hline$\varepsilon_{\text {carb }}$ & $-1.4 \%$ & Fantle and DePaolo 2007 \\
\hline
\end{tabular}

